\title{
LOGÍSTICA DE IMPLEMENTAÇÃO DE BLOCO CIRÚRGICO NA FLORESTA: ATUAÇÃO DO ENFERMEIRO
}

\author{
Logistics of a surgical block implementation in the forest: the nurse's role \\ Logistica de la implementación del bloque quirúrgico en el bosque: actuación del enfermero
}

Cíntia Rachel Gomes Sales ${ }^{1}$, Mona Luisa Sabongi², Valesca Nunes dos Reis', Aline Salheb Alves Pivatti ${ }^{4}$, Agnês Raquel Camisão ${ }^{5}$, Genário Kanashiro Filho ${ }^{6}$

RESUMO: Objetivo: Relatar a experiência de enfermeiros voluntários na Organização da Sociedade Civil de Interesse Público Expedicionários da Saúde no processo de implementação de centro cirúrgico e centro de material e esterilização de hospital de campanha em aldeia indígena na região norte do Brasil. Método: Pesquisa descritiva, narrativa, com abordagem qualitativa, do tipo relato de experiência, realizada entre os meses de setembro e novembro de 2015. Resultados: O processo de estruturação e implementação de um centro cirúrgico e centro de material e esterilização em áreas isoladas conteve cinco etapas e contou com a participação e o envolvimento de enfermeiros desde o planejamento e gerenciamento das atividades até a etapa de execução. Conclusão: O engajamento e o compromisso dos profissionais enfermeiros em todas as etapas contribuem para a garantia da segurança e da qualidade das cirurgias realizadas no paciente indígena, por meio de um trabalho que prima pela organização, sistematização e cientificidade dos processos. Palavras-chave: Enfermagem. Logística. Centros cirúrgicos. Saúde de populações indígenas. Voluntários.

ABSTRACT: Objective: To report the experience of volunteer nurses at the Civil Society Organization for Public Interest "Expedicionários da Saúde" during the implementation process of surgical, supply and sterilization centers of a field hospital in an indigenous village in northern Brazil. Methods: Descriptive and narrative experience report, with a qualitative approach conducted from September to November 2015. Results: The structural process and the implementation of surgical, supply and sterilization centers in isolated areas included five stages, which depended on the participation and involvement of nurses in activities ranging from planning and management to the execution phase. Conclusion: Nurse's professional engagement and commitment in all stages contribute to ensuring the safety and quality of surgeries performed on indigenous patients, an effort that prioritizes organization, systematization, and scientific processes. Keywords: Nursing. Logistics. Surgicenters. Health of indigenous peoples. Volunteers.

RESUMEN: Objetivo: Reportar la experiencia de enfermeros voluntarios en la "Organización de la Sociedad civil de Interés Público Expedicionarios de Salud” en el proceso de la implementación de quirófanos y centros de material de esterilización en hospitales de campaña en aldeas indígenas en la región norte del Brasil. Método: Investigación descriptiva, narrativa, con enfoque cualitativo, de tipo de relato de experiencias realizadas entre septiembre y noviembre del 2015. Resultados: El proceso de estructuración e implementación de un quirófano y centro de material y esterilización en áreas aisladas contiene cinco etapas, y cuenta con la participación y el desarrollo de enfermeros desde la planificación y el gerenciamiento de las actividades hasta la etapa de ejecución. Conclusión: El empeño y lo compromiso de los profesionales enfermeros en todas las etapas contribuyen para la garantía de la seguridad y de la cualidad de las cirugías realizadas en el paciente indígena, por medio de un trabajo que prioriza la organización, la sistematización y los procesos científicos. Palabras clave: Enfermería. Logística. Centros quirúrgicos. Salud de poblaciones indígenas. Voluntarios.

\footnotetext{
'Doutoranda em Ciências da Saúde pela Faculdade de Enfermagem da Universidade Estadual de Campinas (UNICAMP) - Campinas (SP), Brasil. E-mail: prof.cintia.rachel@gmail.com Rua Santos Dumont, 510 - Jardim Paulista - CEP: 79830-150 - Dourados (MS), Brasil.

${ }^{2}$ Especialista em Centro Cirúrgico, Recuperação Pós-anestésica e Centro de Material e Esterilização pelo Centro Universitário Hermínio Ometto (UNIARARAS). Conteudista e Tutora do Ensino à Distância do Instituto de Saúde Integrada (ISI) - Campinas (SP), Brasil.

${ }^{3}$ Doutoranda em Ciências da Saúde pela Faculdade de Enfermagem da UNICAMP. Enfermeira do Hospital Universitário da Universidade Federal de Juiz de Fora (UFJF) - Juiz de Fora (MG), Brasil.

DDoutoranda em Ciências da Saúde pela Faculdade de Enfermagem da UNICAMP. Enfermeira do Hospital Universitário da Universidade Federal de Juiz de Foras
¿Doutorias da Saúde pela Faculdade de Enfermagem da UNICAMP. Professora do Colégio Técnico de Campinas (COTUCA) - Campinas (SP), Brasil.

${ }^{5}$ Doutoranda em Ciências da Saúde pela Faculdade de Enfermagem da UNICAMP. Professora da Faculdade de Enfermagem da Anhanguera - Limeira (SP), Brasil.

${ }^{6}$ Enfermeiro. Coordenador de Enfermagem da Organização da Sociedade Civil de Interesse Público (OSCIP) Expedicionários da Saúde - Campinas (SP), Brasil.

Recebido: 04 maio 2016 - Aprovado: 27 jun. 2016

DOI: $10.5327 / Z 1414-4425201600030007$
} 


\section{INTRODUÇÃO}

A assistência ao povo indígena no Brasil é marcada por desafios que contemplam concomitantemente o acesso universal e equânime aos serviços de saúde, bem como a garantia e o respeito à cultura, crenças, tradições e costumes das diversas etnias presentes no país. A Constituição Federal de 1988, nos arts. 231 e 232, reconhece os direitos dos povos indígenas no que se refere ao direito à terra, à organização social e cultural, evidenciando que cabe ao Estado brasileiro sua garantia, de modo que esses possam exercer sua cidadania em plenitude ${ }^{1}$.

No entanto, foi a Lei Orgânica da Saúde, de 1990, que efetivou o compromisso com a prevenção, promoção, recuperação e reabilitação da saúde indígena no Sistema Único de Saúde (SUS), por meio da formação do Subsistema de Atenção à Saúde Indígena ${ }^{2}$. Em 2002, uma importante iniciativa do Ministério da Saúde de reestruturação de Atenção à Saúde Indígena reafirmou o caráter especializado e diferenciado da atenção integral à saúde para esses povos, instituindo a Política Nacional de Atenção à Saúde dos Povos Indígenas (PNASPI) 3 .

Nesse contexto, diversos movimentos da sociedade brasileira desenvolvem ações com o escopo de ampliar o acesso às práticas de saúde aos povos indígenas. Inserida na perspectiva de promover, complementar e integrar o atendimento cirúrgico especializado por meio de trabalho voluntário a indígenas de áreas isoladas do país, a Organização da Sociedade Civil de Interesse Público (OSCIP) Expedicionários da Saúde (EDS) iniciou em 2003 suas atividades. E foi a partir de articulação e cooperação técnica estabelecidas com instituições e empresas públicas (ex.: Ministério da Defesa, Ministério da Saúde e Fundação Nacional do Índio - FUNAI) e privadas, sob a forma de doações financeiras, de serviços e materiais, que a EDS se estabeleceu e construiu coletivamente um processo de trabalho voluntário, bem como saberes essenciais para contribuir com a promoção da saúde indígena.

O trabalho voluntário, à medida que se desenvolve na prática, agrega valores sociais e coletivos no indivíduo, de acordo com as experiências vividas. A importância da participação em atividades voluntárias reside no fato de despertar ativamente a responsabilidade social, a autonomia e a criatividade nos indivíduos envolvidos ${ }^{4,5}$.

Os enfermeiros, por serem agentes de ações educativas, assistenciais e gerenciais qualificadas em saúde, efetivam sua participação ao integrar a equipe multiprofissional da EDS, com vistas a implementar e desenvolver habilidades técnicas e procedimentos embasados cientificamente, com foco na promoção de um processo de trabalho eficaz e eficiente. Atuando em conformidade com a Resolução do Conselho Federal de Enfermagem (COFEN) $n^{\circ} 424 / 2012^{6}$, os enfermeiros estão envolvidos e inseridos em todas as etapas da expedição, principalmente no que se refere à logística para a montagem de um centro cirúrgico (CC) e centro de material e esterilização (CME) nas aldeias indígenas. Atualmente, além de enfermeiros, a equipe EDS é composta por médicos (anestesista, cirurgião, pediatra, ginecologista, oftalmologista, clínico e ortopedista), farmacêuticos, odontólogos e profissionais de diversas formações que atuam no suporte logístico.

A enfermagem ganha visibilidade e conquista espaços ao demonstrar suas habilidades integrativas e interativas de cuidado, seja no campo da promoção e educação em saúde, seja na sensibilização e mobilização para o desenvolvimento de políticas direcionadas para o bem-estar das famílias e comunidades ${ }^{7}$. O componente holístico enraizado na postura profissional dos enfermeiros, resulta na indissociabilidade da presença desses profissionais e na obtenção de ações, intervenções e processos de trabalho em CC e CME seguros, participativos, contínuos, integrais, individualizados, documentados e avaliados ${ }^{8}$.

No que tange à sua interface com a prática de saúde indígena, o profissional de enfermagem precisa compreender as diferenças étnicas, culturais e do processo de saúde e adoecimento dessa população e, assim, atuar de forma consoante com as reais demandas, respeitando e valorizando os saberes tradicionais e a identidade sociocultural. Além disso, é mister o conhecimento do aparato jurídico-político que legitima, qualifica e garante os diretos desses povos, contribuindo para minimizar o histórico de desigualdades e iniquidades vividos por eles no país ${ }^{9,10}$.

$\mathrm{Na}$ EDS, o profissional enfermeiro desempenha papel fundamental desde a etapa de planejamento/organização até a execução do trabalho, assegurando a operacionalização sistemática dos processos de armazenamento, conservação, distribuição, transporte e manuseio dos materiais e equipamentos a serem utilizados, com o objetivo de manter sua integridade, ou seja, a validade e qualidade desses para que a segurança dos pacientes seja garantida. Os processos foram sistematizados por profissionais com experiência acumulada na prática, embasados e fundamentados cientificamente.

No trabalho da EDS, são elementos-chave: a valorização do profissional enfermeiro, o diálogo e a comunicação bem estabelecida entre os membros da equipe multidisciplinar. As atividades, quando desenvolvidas de forma coletiva e respeitando a formação e participação de cada membro, fazem com que os integrantes incorporem a dimensão afetiva do 
trabalho por compreenderem que o significado de sua pertença no grupo se sobrepõe à de simples executores de serviços ${ }^{11}$.

Sendo assim, inseridos nesse ambiente de evolução de habilidades sociais, o enfermeiro encontra espaço para gerar e compartilhar novos conhecimentos na área de CC e CME em áreas isoladas, bem como a capacitação dessas equipes de saúde acerca de processos hospitalares, com foco no estímulo ao pensamento crítico-reflexivo que contribua para o avanço da prática segura e de alta qualidade.

\section{OBJETIVO}

Relatar a experiência vivenciada por enfermeiros voluntários no processo de implementação de CC e CME de um hospital de campanha em aldeia indígena na região norte do Brasil.

\section{MÉTODO}

Trata-se de uma pesquisa descritiva e narrativa, com abordagem qualitativa, do tipo relato de experiência. O relato foi baseado na experiência de profissionais enfermeiros voluntários na logística de implementação de um CC e CME em aldeia indígena do norte do país, entre os meses de setembro e novembro de 2015, referente à $34^{a}$ Expedição denominada Munduruku. Porém, é importante ressaltar que há 13 anos essa vivência vem sendo aperfeiçoada, possibilitando o desenvolvimento de competências e habilidades técnico-científicas, bem como éticas, sociais e culturais.

O CC e o CME são estruturados com base nos hospitais de campanha de ações humanitárias. Esses hospitais apresentam como característica uma estrutura modular móvel, dotada de equipamentos que lhe garantem autonomia logística em saúde (geradores, iluminação, forração térmica, purificação de água, unidades de climatização, combustível, etc.). Portanto, possuem o potencial de prover cuidados em saúde nos diferentes níveis de atenção em áreas isoladas e intervir em ambientes cujas estruturas de saúde são deficitárias. O CC móvel da EDS conta com seis tendas cirúrgicas para prestar atendimento nas especialidades de oftalmologia, ginecologia e odontologia, além de equipamentos de última geração para garantir a prestação de uma assistência congruente com os princípios da segurança, prevenção e qualidade.

O estudo teve o intuito de descrever as cinco fases logísticas necessárias para que os objetivos da $34^{a}$ Expedição fossem alcançados:
1. Preparo do material e dos equipamentos no centro de distribuição;

2. Preparo logístico da montagem da expedição;

3. Montagem do CC e CME;

4. Desmontagem do CC e CME;

5. Retorno dos materiais e equipamentos no centro de distribuição.

\section{RESULTADOS}

A Associação dos Expedicionários da Saúde iniciou suas atividades há 13 anos, e sua sede está localizada no estado de São Paulo, local que, além das questões administrativas e gerenciais, sedia as reuniões da equipe multiprofissional. Além disso, possui um centro de distribuição $(C D)$ para armazenamento e conservação dos materiais e equipamentos que serão utilizados nas expedições. Desde seu início, o profissional enfermeiro é membro da equipe e participa dos momentos de planejamento e tomada de decisão referente a todas as etapas da expedição.

Atualmente, a EDS apresenta uma equipe de enfermagem composta de um enfermeiro coordenador e um grupo rotativo de enfermeiros voluntários. Cada expedição tem a capacidade de incluir dez enfermeiros voluntários, além do enfermeiro coordenador. Durante a execução da expedição, os enfermeiros voluntários da EDS, juntamente com a equipe de enfermagem do Distrito Sanitário Especial de Saúde Indígena (DSEI), são distribuídos entre os setores de CC, CME, pré-operatório, pós-operatório, ambulatório de ginecologia, ambulatório de oftalmologia, consultórios e triagem.

\section{Preparo do material e equipamentos no centro de distribuição}

A primeira etapa referente ao preparo logístico e operacional é denominada mobilização, e tem início 60 dias antes da etapa da operação. Compreende o conjunto de processos e ações que visam preparar e deslocar todo o pessoal e a carga até o local da operação, bem como montar, colocar em funcionamento e testar todos os equipamentos.

O gerenciamento dos recursos materiais e equipamentos é responsabilidade do enfermeiro coordenador, que inclui a previsão e provisão de materiais e equipamento, ao passo que o processo de conferência, preparo e montagem do material de consumo e permanente é realizado principalmente por enfermeiros voluntários, juntamente com o coordenador. Importante destacar que alguns equipamentos são emprestados por empresas parceiras. 
A dinâmica de trabalho inclui inicialmente uma listagem dos materiais armazenados disponíveis, com vistas ao controle do estoque e da utilização adequada dos materiais para evitar o desperdício. É primordial que o profissional envolvido nessa fase fique atento à qualidade e quantidade do material a ser utilizado, verificando a data de validade e integridade do invólucro, a fim de diminuir riscos e garantir a continuidade da assistência.

A fase de montagem das caixas tipo contêiner com o material que foi previsto para a expedição é denominada romaneio, e leva de dois a três dias para ser finalizada por meio de mutirões. Os insumos são conferidos (data de validade, integridade do invólucro e quantidade), dispostos em embalagens plásticas individuais conforme o tipo e posteriormente acondicionadas em embalagens plásticas maiores dentro da caixa (Figura 1). O preparo com as embalagens plásticas tem o objetivo de evitar o dano ao material em caso de abertura da caixa devido às condições extremas de transporte até o destino final, a aldeia.

A caixa é composta de material plástico duro e impermeável com tampa apresentando diferentes colorações e numeradas, com capacidade de 180 litros. Porém, o ideal é que contenham até $30 \mathrm{~kg}$ para facilitar o transporte. Para cada caixa é realizada uma listagem com os tipos e a quantidade de materiais, que deve ser assinada pelo profissional responsável pela sua montagem. A carga de equipamentos e insumos perfaz um total aproximado de 15 mil kg em cada expedição.

\section{Preparo logístico da montagem da expedição}

O preparo logístico ocorre, aproximadamente, no sexto dia que antecede a expedição. Um dos voluntários é encarregado de liderar a montagem, sendo apresentado a todos os

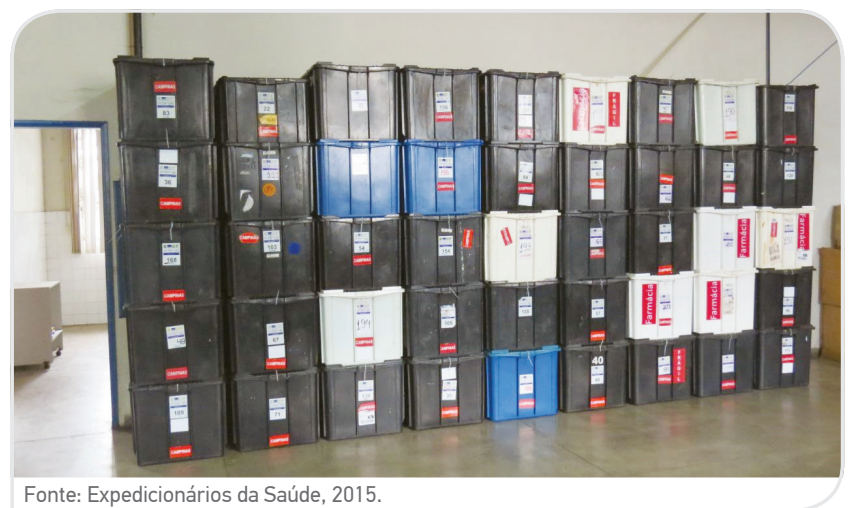

Figura 1. Contêiners de transporte para translado de materiais e equipamentos, alocados no centro de distribuição de Materiais, em Manaus. participantes. Diariamente, a equipe é acompanhada e orientada em relação às atividades designadas, e a comunicação ocorre por meio de rádios e reuniões, conforme a necessidade.

A equipe de montagem é composta de grupos, e cada um é responsável por áreas específicas, tais como: instalação de rede elétrica e geradores, montagem de barracas, limpeza e realocação de mobiliários, equipamentos, medicamentos e insumos. A conclusão da montagem se dá nos dois últimos dias que antecedem a expedição. Nessa ocasião, realiza-se a simulação de carga elétrica plena, utilizando todos os equipamentos elétricos e eletrônicos da expedição, com o objetivo de detectar possíveis sobrecargas. São elaborados planos de contingência, no caso falhas nos geradores, na distribuição de água potável, problemas na rede sanitária, dentre outros. São designados voluntários para reparos elétricos, hidráulicos e serviços gerais. A expedição tem potencial de até 40 cirurgias por dia.

\section{Montagem do centro cirúrgico e do centro de material e esterilização}

As montagems do CC e do CME constituem etapas de extrema importância para a eficácia do processo cirúrgico. Contudo, na expedição o conhecimento técnico-científico do enfermeiro é fundamental para o apoio aos demais voluntários da logística, pois a maior parte desses voluntários são advindos de outras áreas.

Dessa forma, o conhecimento da enfermagem se torna uma ferramenta útil para adequar a estrutura física de um CC e um CME, coerentes com a realidade de um hospital de campanha na floresta, norteando suas ações de acordo com as RDC $n^{\circ} 50$ e $15^{12,13}$. É possível também utilizar ferramentas de apoio, como o processo de enfermagem, que estabelecem e quantificam indicadores de qualidade e quantidade.

O local escolhido para montagem do CC e CME foi um barracão, previamente construído pela comunidade indígena local, que abrigou o CC, CME e o ambulatório de oftalmologia. Estrategicamente, o CME foi alocado ao lado do CC no intuito de otimizar a entrega e retirada de materiais, bem como o processamento dos artigos (Figura 2).

Após a montagem estrutural das barracas, instalação dos equipamentos de ar condicionado e de toda a estrutura elétrica e hidráulica, concluídas pela equipe de logística, o CC e o CME ficaram prontos para receber a montagem final e validação dos equipamentos.

No CC, a equipe de voluntários de enfermagem EDS tem como responsabilidades: administrar e auxiliar o processo de montagem dos equipamentos primordiais para 
o ato cirúrgico; limpeza e organização da sala operatória; abastecimento de insumos; e garantir o controle do fluxo, a segurança e o conforto do paciente. Junto à equipe médica, os enfermeiros administram a agenda de procedimentos, determinando prioridade aos casos de maior complexidade cirúrgica. Além disso, outros fatores são considerados para priorizar o ato cirúrgico, como: idade, doenças crônicas, capacidade de demanda pré-operatória e potencial cirúrgico diário.

Dentre as responsabilidades citadas, atentando para as condições extremas de transporte (terrestre, aéreo e fluvial) que podem ocasionar quebras ou extravios, foi realizada a checagem dos materiais e equipamentos quanto à integridade, além da realização dos testes dos equipamentos eletrônicos.

Juntamente com a equipe de enfermagem do DSEI, os voluntários de enfermagem EDS iniciaram a limpeza terminal das barracas referentes ao CC e CME. Em seguida, realizaram a limpeza concorrente dos mobiliários. Após esses procedimentos, procedeu-se a montagem de duas salas, sendo uma de cirurgia geral e uma de cirurgia oftalmológica. Os equipamentos foram montados pela equipe de engenharia clínica.

No corredor de entrada do CC são dispostas as roupas cirúrgicas e os equipamentos de proteção individuais (EPIs): gorros, máscaras e propés. Embora, atualmente, esse último item esteja em desuso ${ }^{14}$, mantém-se o uso na expedição com a finalidade de reduzir a entrada da sujidade externa do local, e não com o objetivo de prevenir infecções. O lavabo localiza-se em uma área entre as duas salas cirúrgicas. A enfermagem também se responsabiliza pela provisão de escovas cirúrgicas com solução antisséptica e sabão líquido para higienização das mãos.

A estrutura do CME foi baseada em um modelo de barraca de hospital de campanha (Figura 3). Foi dividida em área limpa e suja, de forma a manter a independência entre elas e garantir o fluxo unidirecional, segundo as recomendações da $\operatorname{RDC} n^{\circ} 15^{13}$.

O expurgo é composto de uma pia de inox com duas cubas, duas lavadoras ultrassônicas, além de mesas e bancadas de apoio. Os materiais oriundos do CC, ambulatório de oftalmologia, ambulatório de ginecologia, pediatria e odontologia são recebidos por meio de caixas fechadas, exclusivas ao transporte de materiais sujos, por meio de uma janela, também exclusiva para o recebimento desse tipo de material.

$\mathrm{Na}$ área limpa foram colocadas bancadas, prateleiras e mesas de apoio, nas quais foram disponibilizadas para uso 5 autoclaves gravitacionais a vapor com capacidade de $21 \mathrm{~L}$, 1 autoclave de $54 \mathrm{~L}, 1$ destiladora de água, 1 incubadora de teste biológico e 2 seladoras de grau cirúrgico. Além disso, foram disponibilizadas 2 autoclaves de $21 \mathrm{~L}$ e 2 seladoras reservas. A saída para distribuição dos materiais processados ocorre em caixas fechadas também por meio de uma janela exclusiva.

A montagem final do CME, além dos enfermeiros especialistas e voluntários EDS e do responsável técnico pelo setor, também contou com o apoio da equipe de enfermagem do DSEI. Os enfermeiros EDS e a equipe de engenharia clínica checaram toda parte elétrica e hidráulica, no intuito de garantir o bom funcionamento dos equipamentos e a segurança da equipe.

Somente após conclusão segura da montagem final (Figura 4), na qual todos os equipamentos e insumos foram instalados e alocados, houve a realização dos testes e validação das autoclaves e demais equipamentos, todos com resultados satisfatórios. Tais resultados deram início aos registros documentais dos indicadores de qualidade e quantidade. Salienta-se que indicadores são importantes ferramentas na melhoria dos processos, inclusive os de logística ${ }^{14}$.

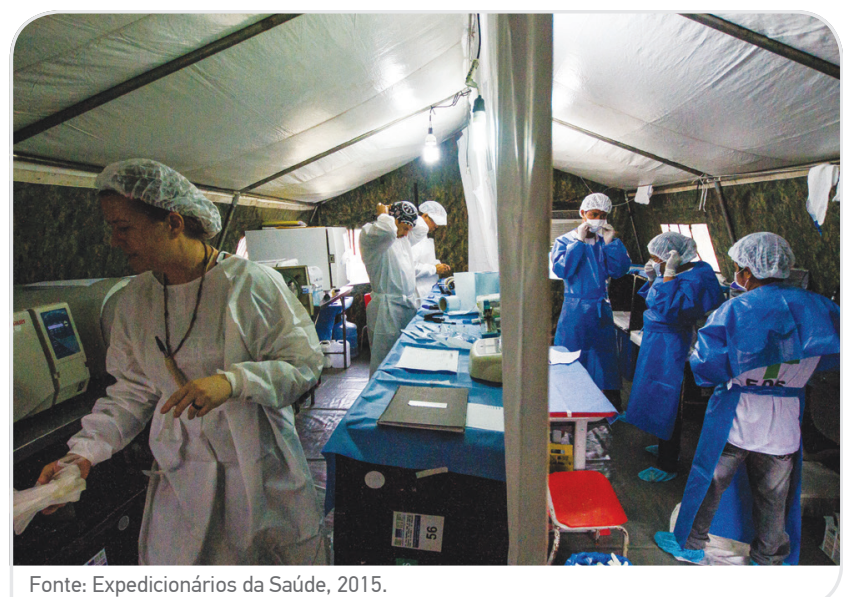

Figura 3. Estrutura interna do centro de material e esterilização, vista para as áreas limpa e suja.
Figura 2. Estrutura externa do Hospital de Campanha, vista

para a entrada e saída do centro cirúrgico.

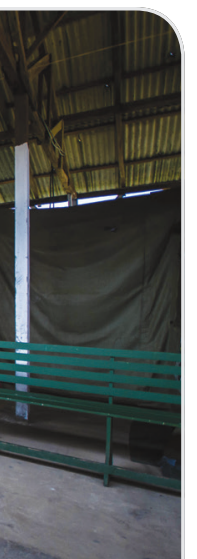

Fonte: Expedicionários da Saúde, 2015. 
O papel do enfermeiro, no que se refere à montagem do setor e também da expedição, facilita toda a logística, gera economia, otimiza os processos e garante a segurança da equipe e dos pacientes.

\section{Desmontagem do centro cirúrgico e do centro de material e esterilização}

No último dia da expedição, iniciou-se a desmobilização, ou seja, a desmontagem dos setores com auxílio da equipe de enfermagem do DSEI. À medida que os procedimentos foram finalizados, todos os equipamentos e materiais foram limpos, secos, embalados e acondicionados dentro das caixas de transporte. Uma caixa com instrumentais cirúrgicos esterilizados foi montada com o objetivo de atender possíveis intercorrências com pacientes e/ou equipe.

Os procedimentos de desmontagem do CC e CME requerem profissionais habilitados e com conhecimentos específicos. Dessa forma, o profissional de enfermagem constituise como peça fundamental também nessa etapa ${ }^{14}$. Na desmontagem, a equipe logística disponibilizou um checklist que facilitou a organização e a conferência dos mobiliários e equipamentos utilizados durante a expedição e, que posteriormente, foram lançados em um software para controlar a saída dos materiais, equipamentos e suplementos que são utilizados durante a expedição e no retorno ao CD.

Nessa etapa, foi realizada a vistoria em conjunto por voluntários de enfermagem e logísticos da EDS, que geraram um relatório de manutenção de equipamentos. A disposição desses equipamentos e mobiliários ocorreu da mesma forma em que foram alocados para o transporte de ingresso, ou

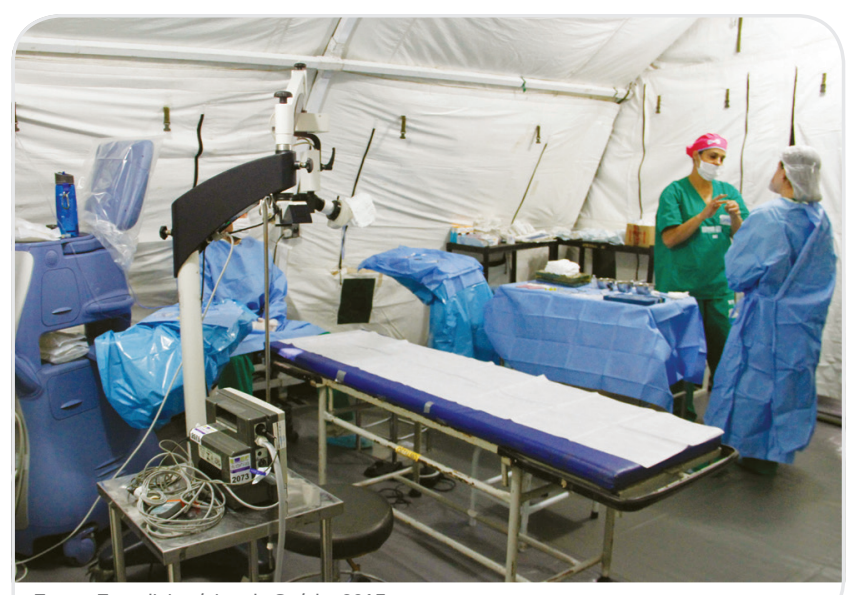

Fonte: Expedicionários da Saúde, 2015.

Figura 4. Estrutura interna do centro cirúrgico, sala operatória montada. seja, em caixas tampadas tipo contêiners, lacradas e identificadas por cores e números. Ao término dessa etapa, outras equipes deram continuidade à desmontagem das barracas e de toda a estrutura elétrica e hidráulica.

\section{Retorno dos materiais e equipamentos para o centro de distribuição}

No dia seguinte, após o término da expedição (Figura 5), todos os materiais romaneados foram acompanhados no retorno ao $\mathrm{CD}$ pela equipe de logísticos da EDS. Como se tratou de logística que envolveu transporte terrestre, fluvial e aéreo, variações climáticas ocasionaram atraso no retorno da carga, que levou 20 dias para chegar ao CD.

Após o acondicionamento das caixas no $\mathrm{CD}$ pela equipe de logística da EDS e profissionais da transportadora, iniciou-se o processo de desmobilização da carga. Tal processo ocorreu por meio de mutirões envolvendo equipe de enfermagem e logísticos da EDS.

$\mathrm{Na}$ etapa de desmobilização, todas as caixas romaneadas foram abertas para conferência dos materiais e insumos quanto à quantidade e integridade, e reorganizados no CD. Os equipamentos emprestados à EDS foram devolvidos às empresas de origem, e os equipamentos pertencentes à EDS foram encaminhados para manutenção preventiva e corretiva.

Nessa fase de conclusão da expedição, observou-se que algumas caixas de transporte foram danificadas. Entretanto, não houve comprometimento do conteúdo interno e tampouco extravio.

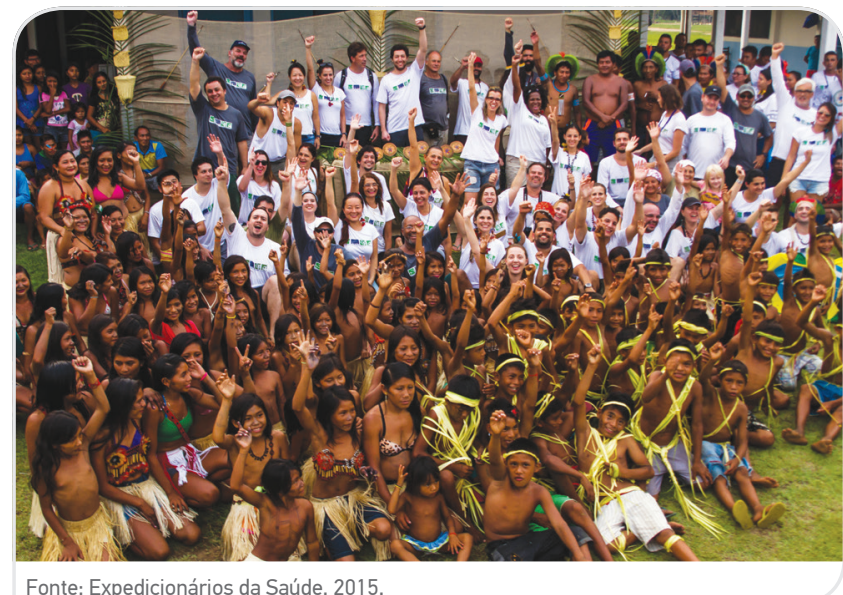

Figura 5. Momento de confraternização da equipe de voluntários Expedicionários da Saúde e indígenas da comunidade Munduruku e Kaiapó, após encerramento da 34ª Expedição dos Expedicionários da Saúde. 


\section{DISCUSSÃO}

Uma grande parcela da população não tem acesso a serviços de atendimento cirúrgico, visto que no mundo há um déficit de cirurgiões, anestesistas e obstetras. Historicamente, organizações não governamentais (ONGs) vêm tentando suprir essa necessidade tão específica. Porém, a exata contribuição desses órgãos não tem sido bem documentada ${ }^{15}$.

Entre 2008 e 2012 todos os continentes apresentaram taxas de trabalho voluntário significativo, com média de $37,9 \%$ na Oceania, 22,8\% nas Américas, 19,7\% na Ásia, 17,2\% na Europa e 17,0\% na África. Esses dados sinalizam que a participação ativa e regular de voluntários é vital para sustentar as atividades das comunidades e organizações sem fins lucrativos ${ }^{16,17}$.

Uma revisão integrativa realizada com o objetivo de enumerar e descrever as ONGs que prestavam atendimento cirúrgico encontrou 403 atuando em 139 países, sendo que apenas $2 \%$ atendem em centros cirúrgicos móveis em áreas rurais ou remotas $^{15}$. A EDS não foi incluída nessa revisão. Entretanto, destacamos que ela faz parte de uma minoria, que nesse caso em específico, monta um hospital de campanha na floresta.

O trabalho de enfermagem com indígenas se baseia em duas premissas básicas: na habilidade técnica do profissional e no relacionamento de confiança. Em centros de suporte à saúde indígena (CASAIs), a equipe de enfermagem planeja a assistência e as ações que deverão ser realizadas com os pacientes indígenas, o que inclui gerir o processo de transporte, alimentação e estadia, já que esses precisam se deslocar a grandes distâncias para ter acesso ao atendimento de saúde $^{18}$. Contudo, a EDS se mobiliza e adequa sua logística para que o atendimento cirúrgico ao indígena seja ofertado dentro da floresta, junto às aldeias previamente selecionadas, de acordo com a demanda e o apoio da FUNAI, da Secretaria Especial da Saúde Indígena (SESAI) e do DSEI.

A medição do bom desempenho de um CC está diretamente relacionada à qualidade de seus próprios processos e dos serviços que o apoiam, isto é, resulta da combinação entre instalações físicas, tecnológicas e equipamentos adequados e a atuação habilitada, treinada e competente da equipe de enfermagem. Sendo assim, para manter a agilidade e organização do processo cirúrgico, é necessário que os membros da equipe de enfermagem possuam grande conhecimento e experiência na área ${ }^{19}$.

Por se tratar de um ambiente diferenciado, com foco na saúde indígena, a dinâmica do trabalho e do relacionamento profissional em uma expedição necessita ocorrer de maneira consensual, com uma equipe capacitada e preparada, apta a enfrentar as exigências e os desafios imposto pelas mudanças do ambiente, da cultura, da tecnologia, das questões sociopolíticas e econômicas no âmbito da saúde pública ${ }^{20}$. Visto que não há muita publicação brasileira sobre o trabalho de enfermagem no que diz respeito à logística de expedição em saúde, especialmente no que se refere ao atendimento em áreas isoladas, percebe-se a necessidade de mais estudos nessa área.

Nessa perspectiva, a EDS reconhece e valoriza a importância do profissional de enfermagem e, por isso, mantém parceria com uma equipe de voluntários enfermeiros que participam ativamente de todas as etapas na logística de uma expedição. Esses profissionais compreendem a influência de sua colaboração, a qual suplanta a disponibilidade física, pois nesse contexto o conhecimento técnico e científico, a criatividade e o dinamismo são fundamentais para auxiliar a equipe médica e, assim, obter sucesso nos procedimentos cirúrgicos que serão prestados aos povos indígenas.

\section{CONCLUSÃO}

A possibilidade de atuar como enfermeiros voluntários junto a povos indígenas de áreas isoladas contribui sobremaneira para o desenvolvimento de competências e habilidades humanas e sociais. O conhecimento técnico baseado em evidências e aprimorado a partir das experiências de logística na implementação de CC e CME só é possível devido ao engajamento e compromisso dos profissionais envolvidos. Esses têm como expoente máximo a garantia da segurança do paciente indígena, por meio de um trabalho que prima pela organização, sistematização e qualidade dos processos.

As etapas de planejamento e gestão que antecedem a expedição propriamente dita são fundamentais para o controle dos processos de trabalho de forma a minimizar e/ou impedir a ocorrência de danos evitáveis. Além disso, o registro sistemático das ações realizadas em todas as etapas é ferramenta valorizada e obrigatória na EDS, já que permite avaliar os resultados, gerar indicadores e qualificar a assistência realizada.

Implementar um CC e CME na floresta torna-se viável a partir do momento em que há rigor no cumprimento das normas técnicas. Cada profissional envolvido tem ciência da sua responsabilidade, tanto técnica quanto ética, para que os procedimentos cirúrgicos sejam executados com os mesmos cuidados dos seus ambientes de trabalho de origem.

Os obstáculos enfrentados pelo deslocamento e pelas barreiras geográficas e culturais são superados pela composição multidisciplinar da EDS, pela inclusão dos profissionais e 
trabalhadores de saúde dos DSEIs, pelas parcerias estabelecidas com órgãos governamentais e da iniciativa privada e, acima de tudo, pelo respeito à cultura e às tradições dos povos indígenas.

A EDS visa criar um modelo referencial de atendimento médico especializado a populações geograficamente isoladas, facilitando o acesso a um atendimento de qualidade. Dessa forma, tem como missão levar atendimento médico, principalmente cirúrgico, até as populações indígenas isoladas, com excelência na qualidade de serviços e gestão responsável. Sendo assim, ao se inserir em contextos com características completamente diferentes do usual, conquistar espaço e ter definido seu papel de atuação, o enfermeiro demonstra a importância da enfermagem enquanto arte, ciência e prática para o alcance de ações em saúde eficazes em diferentes povos.

\section{REFERÊNCIAS}

1. Brasil. Constituição da República Federativa do Brasil: texto constitucional promulgado em 5 de outubro de 1988, com as alterações adotadas pelas Emendas constitucionais $\mathrm{n}^{0 \mathrm{~s}} 1 / 1992$ a 86/2015, pelo Decreto legislativo no $186 / 2008$ e pelas Emendas constitucionais de revisão ${ }^{\circ 5} 1$ a 6/1994. 45a ed. Brasília: Câmara dos Deputados, Edições Câmara; 2015.

2. Brasil. Lei no 8.080 , de 19 de setembro de 1990 . Dispõe sobre as condições para a promoção, proteção e recuperação da saúde, a organização e o funcionamento dos serviços correspondentes e dá outras providências. Brasília: Diário Oficial da União, 20 set. 1990. Seção 1, p. 18055.

3. Brasil. Política nacional de atenção à saúde dos povos indígenas. Brasília: Fundação Nacional de Saúde; 2002 [acesso em 2016 mar 13], 40 p. Disponível em: <http://bvsms.saude.gov.br/bvs/publicacoes/ politica_saude_indigena.pdf>

4. Fior CA, Mercuri E. Formação universitária e flexibilidade curricular: importância das atividades obrigatórias e não obrigatórias. Psicol Educ. 2009;29:191-215.

5. Nunes DCG. Qual a importância do trabalho voluntário para a sustentabilidade de organizações não-governamentais? [dissertação]. Programa de Pós-Graduação em História, Política e Bens Culturais. Rio de Janeiro: Fundação Getúlio Vargas; 2009.

6. Conselho Federal de Enfermagem (COFEN) [Internet]. Resolução COFEN n० 424, de 19 de abril de 2012. Normatiza as atribuições dos profissionais de enfermagem em Centro de Material e Esterilização e em empresas processadoras de produtos para saúde. Brasília: Diário Oficial da União, 23 abr. 2012. Seção 1, p. 186.

7. Backes DS, Backes MS, Erdmann AL, Büscher A. 0 papel profissional do enfermeiro no Sistema Único de Saúde: da saúde comunitária à estratégia de saúde da família. Ciênc Saúde coletiva. 2012;17(1):223-30.

8. Fonseca RMP, Peniche ACG. Enfermagem em centro cirúrgico: trinta anos após criação do Sistema de Assistência de Enfermagem Perioperatória. Acta Paul Enferm. 2009;22(4):428-33.

9. Oliveira JWB, Aquino JM, Monteiro EMLM. Promoção da saúde na comunidade indígena Pankararu. Rev Bras Enferm. 2012;65(3):437-44.
10. Silva NC, Gonçalves MJF, Lopes Neto D. Enfermagem em saúde indígena: aplicando as diretrizes curriculares. Rev Bras Enferm. 2003;56(4):388-91.

11. Braga EM, Berti HW, Risso ACMCR, Silva MJP. Relações interpessoais da equipe de enfermagem em centro cirúrgico. Rev SOBECC. 2009;14(1):22-9.

12. Brasil. Resolução RDC n 50, de 21 fevereiro de 2002. Regulamento técnico para planejamento, programação, elaboração e avaliação de projetos físicos de estabelecimentos assistenciais de saúde. Brasília: Diário Oficial da União, 20 mar. 2002.

13. Brasil. Resolução RDC no 15, de 15 de março de 2012. Dispõe sobre requisitos de boas práticas para o processamento de produtos para saúde e dá outras providências. Brasília: Diário Oficial da União, 19 mar. 2012. Seção 1, p. 43-6.

14. Sociedade Brasileira de Enfermeiros de Centro Cirúrgico, Recuperação Anestésica e Centro de Material e Esterilização (SOBECC). Práticas Recomendadas SOBECC. 6a ed. São Paulo: SOBECC; 2013.

15. Ng-Kamstra JS, Riesel JN, Arya S, Weston B, Kreutzer T, Meara JG, et al. Surgical non-governmental organizations: global surgery's unknown nonprofit sector. World J Surg. 2016;40(8):1823-41.

16. Charities Aid Foundation. World Giving Index 2013: a global view of giving trends [Internet]. $2013 \mathrm{dez}$ [citado 2016 mar. 28]. Disponível em: <https:// www. cafonline.org/PDF/WorldGivingIndex2013_1374AWEB.pdfs

17. Snyder M, Omoto AM. Volunteerism: social issues perspectives and social policy implications. Soc Issues Policy Rev. 2008;2(1):1-36.

18. Ribeiro $\mathrm{AA}$, Fortuna $\mathrm{CM}$, Arantes $\mathrm{CIS}$. Nursing work in an indigenous support institution. Texto Contexto - Enferm. 2015;24(1):138-45.

19. Santos MC, Rennó CSN. Indicadores de qualidade da assistência de enfermagem em centro cirúrgico: Revisão Integrativa da Literatura. RAS. 2013;15(58):27-36.

20. Freitas NQ, Dissen CM, Sangoi TP, Beck CLC, Goulart CT, Marion R. 0 papel do enfermeiro no centro cirúrgico na perspectiva de acadêmicas de enfermagem. Rev Contexto \& Saúde. 2011;11(20):1133-6. 